pared with corresponding figures furnished by some other good specimens of clays previously examined, the opinion formed is that many of them could hardly be surpassed in purity and quality. An important and interesting fact will be at once noted regarding the relative values of these deposits; viz., with a few exceptions the specimens are remarkably uniform in character and on the whole may be considered as representing a high standard of perfection now reached in the progress of a great industry.

On comparing the figures of the clays marked No. 6 to No. 8, with those yielded by the samples obtained from other deposits, it is evident that there is a great difference in the proportion of iron contained in these minerals. A corresponding difference appears in the general character of the clays, notably when compared with those marked Nos. I to 4 , and those marked Nos. 9 to I 2 , which are finer and possess a much better color. The latter variation may be partly owing to a difference in the nature and extent of the surrounding beds, or to some local circumstances affecting the cleaning of the material and the nature of the clay produced. The presence of a comparatively high percentage of alkalies in the clays Nos. 5 and 8 points to the fact that the clay is associated with an unusually large quantity of unaltered feldspar and some micas, while the potash content found on analysis indicates the presence of "muscovite," one of the characteristic minerals of the crystalline rocks, granites, etc. This information leads one to suppose that the clay has been mined near some point of gradation of the true kaolin and the primary bed: a corresponding increase of the constituents of the original rock is noticed, which serves to confirm this impression.

With regard to the question of the properties imparted to papers by the use of different kinds of fillers, one can hardly differentiate between values of the best qualities: at least, when dealing with highclass grades, such as the above mentioned. One might go further, however, and say that more attention should be given by consumers to the question of the state of fineness of the clays acquired for the purpose of loading. For example, clays are not uncommonly found on the market which to all intents and purposes are equal in purity and color to the wellknown brands of standard clays, but, on a physical examination, they are proved to contain as much as 8 to $\mathrm{I} 2$ per cent. of grit, and sometimes even I 8 per cent. Again, the question of difference in price is often very little, the rate being but slightly lower than that demanded for really high-grade material.

It will be readily understood from this digression that the absolute analytical figures, unless interpreted by a skilled chemist, do not accurately gauge the entire value of the clay, because the component parts of the foreign débris, usually associated with clay, bears a close relationship to the ratio of the constituent elements in the true kaolin itself. It behooves buyers, therefore, to attach due importance to the classification which is based on the composition fur- nished under this system of mechanical separation of the gritty particles.

AYNSOME TECHNICAL I,ABORATORIES, LANCASHIRE, ENGLAND.

\section{A SCHEME FOR THE RAPID ANALYSIS OF CEMENT.}

By Clarence N. WiIey and W. A. Érist. Received June 15, 1911.

Chemists who are engaged in the manufacture or testing of Portland cement have long wished that they could obtain a complete analysis of a cement, the composition of which was in question, without proceeding with the tedious and lengthy method generally employed. This method, in order to be accurate, calls for the solution of the cement in $\mathrm{HCl}$, evaporation to dryness, followed by a short baking in order to render the silicic acid entirely dehydrated and insoluble. This evaporation must be carried out with more or less care, because if the evaporation is made at too great a temperature or in too hasty a manner, and extreme care is not taken, the gelatinous silicic acid, in being freed from its water, will spatter and danger of loss is incurred. The operation requires at best from three to four hours, and if all of the silicic acid is not dehydrated, a loss is bound to occur through silica passing through the filter.

The old method for the separation of iron and alumina, by means of fusion with potassium acid sulphate, is also a source of annoyance to the busy chemist. Fusion must be carefully watched until the liquid stage has been reached, and even then, if the heat is not carefully adjusted, frothing or boiling over is frequent. To make this fusion requires time and attention taken from other, perhaps more important, work. The solution of the cake is again an occasion of delay and the reduction of the iron present, to be properly accomplished, requires several hours and, if the iron is in large quantity, even longer.

The determination for magnesia also consumes much time and it is the general custom to allow the granular crystalline precipitate of magnesium ammonium phosphate to completely subside so that filtration may be speedily accomplished.

A complete analysis of cement, therefore, covers a period of two days' time, although it can be done in the course of one day by careful manipulation. The authors have been searching for some time to find a method whereby accurate results could be obtained in a much shorter time. They had already adopted the schemes for the determination of magnesia and the separation of iron and alumina, which will be described later, but had found no suitable method for the rapid accurate determination of silica.

Some time ago there appeared in Tonindustrie Zeitung, 35, 265, a method described by C. Hentschel, whereby silica can be accurately separated from cement by means of acetic acid and in a very short time. Here, at last, appeared the solution of our problem, and upon the first trial of this method we knew that the operation of cement analysis could be accomplished in a few hours' time.

The method described by Hentschel is as follows: 
"One gram of cement is ground to powder in a porcelain dish; a little water and Io cc. acetic acid are added. The mixture is then heated under constant stirring for about I5-20 minutes, till the cement has settled and no particles are floating around any more. Now more distilled water and as much dilute $\mathrm{HNO}_{3}$ are added as is necessary to keep the iron and the silicates of aluminum in solution. The mixture is heated again for 5 minutes. It is then filtered off with accompanying decantation of the residue silica, washed in hot water and filtered again. If sufficient care is taken, the filtered silica will always be free from iron and aluminum silicates. After washing the silica is ignited and then weighed. After heating in the water bath, the solution must be treated with $\mathrm{HNO}_{3}$ and not $\mathrm{HCl}$, as this would prolong the test. The determination can be made within one and onefourth hours, whereas any of the other methods take at least 3 to 4 hours."

After repeated trials, the authors have decided that there is no difference in the time of operation, whether $\mathrm{HNO}_{3}$ or $\mathrm{HCl}$ be added to the liquid after solution by acetic acid. Also, it has been determined that but 5-6 minutes are required for digestion if 0.5 gram of material is used and the results on the smaller amount are equally accurate.

The entire method for the complete analysis of Portland cement now in use by the writers is as follows: Weigh 0.5 gram of cement into a porcelain casserole, add water and then so cc. glacial acetic acid. Stir with a glass rod until all lumps are broken up, then place on the hot plate and digest, stirring from time to time until no particles of cement remain. This requires about 5 minutes, and care should be taken that the contents do not boil over. To this solution add a dilute solution of $\mathrm{HCl}$ until the reddish color is dissipated. Filter and wash thoroughly with hot water, ignite the precipitate, blast for a few minutes, cool and weigh. After a little experience this operation can be completed in 30 minutes.

The filtrate from the silica is now made up to 200 cc. in a graduated flask and aliquot portions separated. To the first is added a few drops of $\mathrm{HNO}_{3}$ and then $\mathrm{NH}_{4} \mathrm{OH}$ until the iron and alumina are precipitated as hydrates. Set the solution aside for a few minutes on the hot plate until subsidence takes place, filter, wash, ignite and weigh as oxids. Alumina and iron are separated in the second portion by means of the Zimmermann-Reinhardt method. Heat the solution to boiling, reduce the ferric chlorid by adding, drop by drop, a solution of stannous chlorid ${ }^{x}$ until the solution becomes colorless. Cool, make up to $300 \mathrm{cc}$, and add $25 \mathrm{cc}$. $\mathrm{MnSO}_{4}$ solution.2 Stir vigorously, add to $\mathrm{cc}$. $\mathrm{HgCl}_{2}$ (saturated solution) and titrate the solution at once with $\mathrm{KMnO}_{4}$.

The filtrate from the first portion is now made up to about $400 \mathrm{cc}$, the lime precipitated at $\mathrm{Ca}_{2} \mathrm{C}_{2} \mathrm{O}_{4}$,

${ }^{1}$ Stannous chlorid solution: 25 grams stannous chlorid are dissolved in $100 \mathrm{cc}$. concentrated $\mathrm{HCl}$ and diluted with water to 1 liter.

$2 \mathrm{MnSO}_{4}$ solution: 67 grams crystalline $\mathrm{MnSO}_{4}, 4 \mathrm{H}_{2} \mathrm{O}$ are dissolved in 500-600 cc, water, $138 \mathrm{cc}$. phosphoric acid (sp. gr. 1.70 ) and $130 \mathrm{cc}$ concentrated sulfuric acid (sp. gr. 1.82) are added and the mixture diluted to 1 liter. filtered, washed and titrated with $\mathrm{KMnO}_{4}$ in the usual manner.

The filtrate from the lime is boiled down in an evaporating dish to about $200 \mathrm{cc}$, acidified with $\mathrm{HCl}$ and washed into an Erlenmeyer flask. Add sodium ammonium phosphate solution and about $5 \mathrm{cc}$. $\mathrm{NH}_{4} \mathrm{OH}$ and cool in running water, shaking vigorously, until the precipitate begins to form. Then add about I 5 cc. of $\mathrm{NH}_{4} \mathrm{OH}$ and shake for about ro minutes. Allow the precipitate to settle for about 5 minutes and filter. Wash with the usual solution, ignite and weigh as $\mathrm{Mg}_{2} \mathrm{P}_{2} \mathrm{O}_{7}$.

While the above procedure has been carried on, another sample has been started for the determination of sulphuric anhydride. In this case take I gram of cement, digest with acetic acid as before, and add dilute $\mathrm{HCl}$ before filtering. The filtrate is heated to boiling and a few cc. of alcohol are added. BaSO, is precipitated by means of $\mathrm{BaCl}_{2}$ solution and the beaker stood on the hot plate for one-half hour, at the end of which time all of the $\mathrm{BaSO}_{4}$ will have subsided and filtration can be speedily accomplished.

From a large number of determinations we have found that it requires from 2 to 2.5 hours to make a complete analysis of cement and our results have agreed very closely with those obtained by means of the usual method. These results are sufficiently accurate for control work and the great saving in time makes this short method of much value. In the routine of the cement works laboratory, the daily analysis of the finished cement becomes very monotonous because of the fact that it may be considered "post-mortem" work, by which is meant that the composition of the cement cannot now be altered. Where large clinker storages are in use, the clinker may not be ground for several weeks after it is discharged from the kilns. It is thus seen that analysis of the finished cement is of very little value except for purpose of record and comparison with the physical tests.

Following are given several results of analyses made by both methods:

\begin{tabular}{|c|c|c|c|c|c|c|}
\hline & \multicolumn{3}{|c|}{ Regular. } & \multicolumn{3}{|c|}{ Acetic acid. } \\
\hline & (1) & (2) & (3) & (1) & (2) & (3) \\
\hline $\mathrm{SiO}_{2}$, & 21.42 & 22.74 & 21.50 & 21.34 & 22.94 & 21.40 \\
\hline $\mathrm{Al}_{2} \mathrm{O}_{3}$ & 7.38 & 7.24 & 7.66 & .7 .34 & 6.98 & 7.76 \\
\hline $\mathrm{Fe}_{2} \mathrm{O}_{3},$. & 2.60 & 2.72 & 2.84 & 2.60 & 2.72 & 2.84 \\
\hline $\mathrm{CaO} \ldots \ldots \ldots$ & 62.40 & 61.46 & 62.18 & 62.40 & 61.85 & 62.33 \\
\hline MgO........ & 2.41 & 2.26 & 2.51 & 2.52 & 2.26 & 2,45 \\
\hline $\mathrm{SO}_{3}$. & 1.33 & 1.45 & 1.27 & 1.34 & 1.45 & 1.27 \\
\hline Ig. loss...... & 1.54 & 1.38 & 1.14 & 1.54 & 1.38 & 1.14 \\
\hline
\end{tabular}

Nos. I and 3 were completed in 2.5 hours and in No. 2 the $\mathrm{SiO}_{2}, \mathrm{R}_{2} \mathrm{O}_{3}$ and $\mathrm{CaO}$ results were obtained in 45 minutes after the sample was weighed. We have obtained results of complete analyses which have checked closer than the above, but these are given as they represent the average of our experience. Determinations of $\mathrm{SiO}_{2}$ completed in 20 minutes check as follows with $\mathrm{SiO}_{2}$ evaporations:

\begin{tabular}{ccc}
\multicolumn{3}{c}{ Regular. } \\
$\begin{array}{ccc}\text { (1) } & (2) & (3) \\
21.54 & 22.94 & 21.56\end{array}$
\end{tabular}

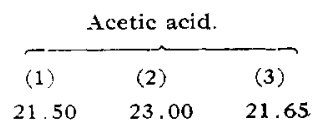


Efforts have been made to apply this acetic acid scheme for the decomposition of raw material, shale and clay, and limestone, but so far have not been successful. Evaporation after fusion must be practiced to render the silica insoluble, but it is our hope to find a method whereby this determination may be considerably shortened.

LABORATORY OF THE

Atlantic \& Gtif Portland Cement Co,

RAGLAND, ALA.

THE DETERMINATION OF SULPHUR IN COAL BY MEANS OF JACKSON'S CANDLE T URBIDIMETER.

BY HENRY F. MUER.

Received May 5, 1911

The candle turbidimeter is an apparatus originally devised by D. D. Jackson for the purpose of measuring the turbidity of water, and thereby furnishing a means of comparing different waters in that respect. ${ }^{x}$ The simplicity and ease of operation of this apparatus led to its adoption as a standard for that purpose. ${ }^{2}$ Further experiments demonstrated the possibility of calibrating the apparatus for measuring the turbidity produced by certain precipitates, such as barium sulphate and calcium oxalate, thus indicating the amount of sulphate, or lime, present in the tested solution. Tables of values were prepared and the apparatus was adopted by the U. S. Geological Survey for use in the field assay of water. 3

The apparatus comprises a support for a standard candle, in which the candle is kept at a constant height by means of a spring. This is set upright in a base, to which is attached the support for the removable holder of the graduated tube used to measure the depth of the turbid solution necessary to efface the image of the candle flame. Naturally, the more turbid the liquid, the less will be required to efface the image of the flame.

Although the results obtained photometrically cannot be expected to show the same exactness as the gravimetric methods, such an apparatus will, if properly used, give very satisfactory results, and is especially advantageous in routine work when large numbers of samples have to be examined daily and rapidly. Such a case is the determination of "volatile" sulphur in coal. By means of the bomb calorimeter and the candle turbidimeter this may be determined in about ten minutes, whereas by the gravimetric method the result would not be obtained in less than two hours. This apparatus is equally useful in the routine determination of the $\mathrm{SO}_{3}$ content of cements and boiler waters.

When the writer began the use of the candle turbidimeter in routine coal work it was deemed desirable to make frequent gravimetric check determinations in order to note possible errors. In the course of these control tests it was found that the results obtained with the turbidimeter did not always correspond with the gravimetric results. The differ-

1 Techn. Quarterly, 13, 278 (1900)

2 Stand. Meth. Water Anal., Am. Pub. Health Assn., 1905.

3 L. S. Geol. Sur. W. S. Paper 161, 1905. ences seemed greater than was desirable, and an investigation was begun in order to learn the cause.

A re-standardization of Jackson's table was first attempted. For this purpose a sodium sulphate solution was prepared and carefully standardized gravimetrically. It was of such a strength that I

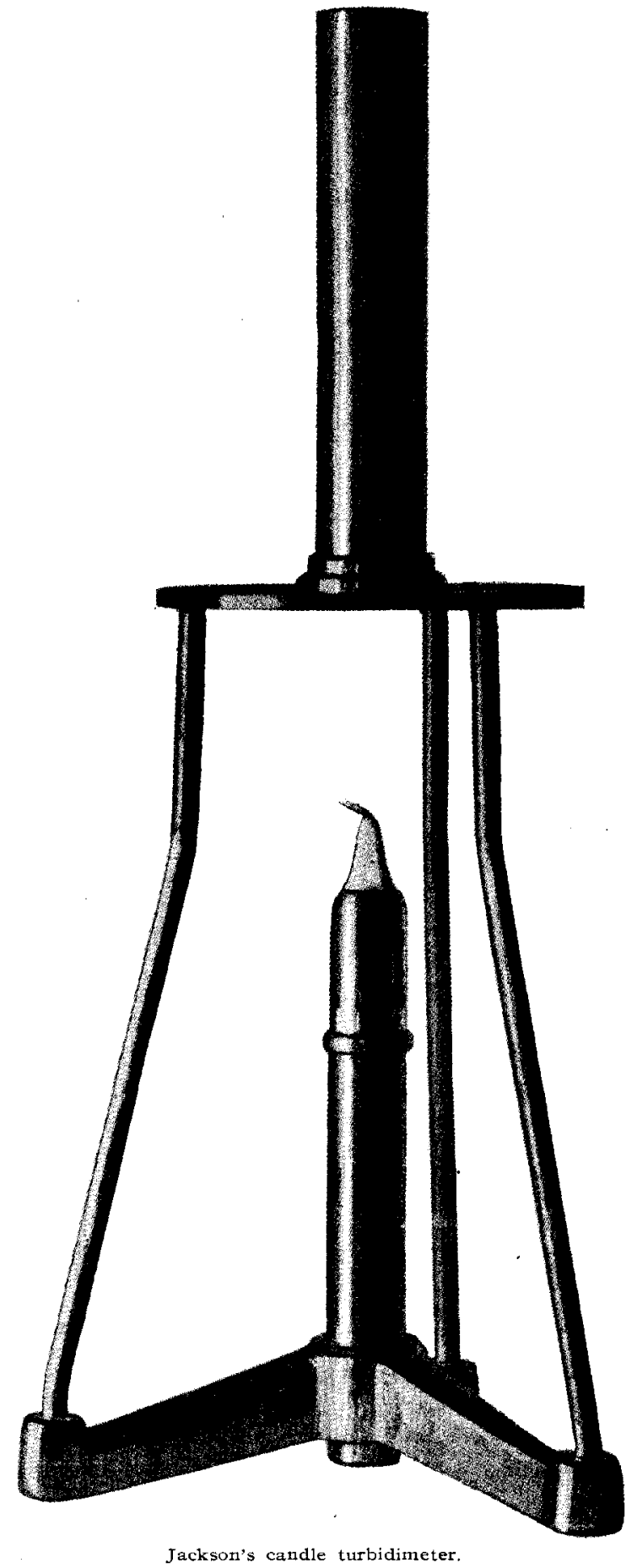

cubic centimeter contained I milligram of sulphur, or 4.43 milligrams of sodium sulphate. The flasks and burettes chosen were all in agreement with each other, but when aliquot parts of the sulphate solution were acidified and diluted to roo cubic centimeters, and tested with the turbidimeter, it was 